\section{How much of the decrease in cancer death rates in the United States is attributable to reductions in tobacco smoking?}

Michael J Thun, Ahmedin Jemal

\section{Reductions in tobacco smoking are a major factor in the decrease in cancer mortality rates}

ta is difficult to quantify the benefits of large scale, preventive interventions taken in the past, because the size of the benefit depends on assumptions about what might have happened had there been no intervention. For example, if one wishes to measure how much of the decrease in cancer death rates in the United States is attributable to reductions in tobacco smoking, the most conservative approach is to consider only the time period during which cancer death rates actually decreased. This limits consideration to the observed decrease in overall cancer death rates that occurred among men (but not women) between 1991, the year when the age standardised cancer death rate peaked in the overall US population, and 2003, the most recent year for which final mortality data are currently available. ${ }^{1}$ While it seems prudent to base the estimate only on observed data and only during the time period when cancer death rates actually decreased, this approach greatly underestimates the full impact of reductions in smoking on cancer death rates over the preceding three decades. It fails to consider first the attenuation of the increase and then the levelling off of the death rates from smoking related cancers that occurred before their actual decline. A different approach is needed to take into account what would likely have happened to cancer death rates over the last half century, had the health community not intervened to discourage cigarette smoking.

\section{LUNG CANCER}

We used both of the approaches mentioned above to estimate how much reductions in tobacco smoking have contributed to the decrease in mortality rates from cancer in the United States. We also used a third, related method to consider the impact of smoking reduction on the number of deaths from cancer.
In all analyses, we used lung cancer as a proxy to represent the total impact of cigarette smoking on all cancer mortality. We recognise that active smoking causes many other cancers besides lung cancer, including cancers of the oral cavity, nasal cavity and paranasal sinuses, nasopharynx, oro- and hypopharynx, larynx, oesophagus (squamous and adenocarcinoma), pancreas, stomach, liver, kidney, renal pelvis, ureter, urinary bladder, uterine cervix, and acute myeloid leukaemia. ${ }^{2}$ However, lung cancer deaths comprise attributable cancer deaths in the United States, ${ }^{3}$ and cigarette smoking accounts for a larger fraction of lung cancer deaths in men (88\%) and women $(72 \%)$ than any other smoking-attributable cancer except laryngeal cancer. ${ }^{3}$ The trend in mortality from laryngeal cancer is similar to that from lung cancer, but it accounts for only about $1 \%$ as many deaths. ${ }^{14}$ Because of the high attributable fraction for lung the majority $(80 \%)$ of all smoking- cancer, the temporal trends in lung cancer mortality are much less influenced by changes in other risk factors or by the consequences of early detection and/or treatment than are other smoking-attributable cancers.

Our first approach considered only the observed change in death rates from all cancers combined and from lung cancer from 1991 to 2003. As shown in table 1 , the overall cancer death rate decreased by $16.1 \%$ in men and by $8.4 \%$ in women from 1991 to 2003. During the same period, the lung cancer death rate decreased by $20 \%$ in men but increased-rather than decreased-by $9.6 \%$ in women. Based on the absolute change in the death rates, it can be seen that the decrease in the lung cancer death rate in men accounted for $40 \%$ of the decrease in the overall cancer death rate in men. In contrast, none of the decrease in the all cancer death rate in women was accounted for by lung cancer. In fact, the trend in lung cancer was in the opposite direction of the trend in overall cancer death rates in women. The decrease in overall cancer mortality in women would have been larger than it was, had there not been a small increase in lung cancer mortality.

As mentioned above, the first approach ignores the levelling off of cancer death rates that occurred in men since the mid-1970s, and in women since 1990. Figure 1 depicts the observed trends in the age-standardised lung cancer death rate as solid lines for men (red) and women (blue) from 1930 through 2003. As shown, the observed lung cancer death rate (per 100000 ) in men increased steeply from 1950-1975, then increased more gradually through 1990, before beginning to decrease. Among women the lung cancer death

Table 1 Overall and lung cancer deaths rates in 1991 and 2003

\begin{tabular}{|c|c|c|c|c|}
\hline & \multicolumn{2}{|c|}{ Death rate (per 100000) } & \multirow{2}{*}{$\begin{array}{l}\text { Percentage } \\
\text { change }\end{array}$} & \multirow{2}{*}{$\begin{array}{l}\text { Absolute } \\
\text { change }\end{array}$} \\
\hline & 1991 & 2003 & & \\
\hline \multicolumn{5}{|c|}{ Observed data* } \\
\hline \multicolumn{5}{|c|}{ All cancers } \\
\hline Men & 279.1 & 234.1 & $-16.1 \%$ & -45.0 \\
\hline Women & 173.3 & 160.5 & $-8.5 \%$ & -14.8 \\
\hline Both & 215.1 & 190.1 & $-11.6 \%$ & -25.0 \\
\hline \multicolumn{5}{|l|}{ Lung cancer } \\
\hline Men & 89.9 & 71.9 & $-20.0 \%$ & -18.0 \\
\hline Women & 37.6 & 41.2 & $+9.6 \%$ & +3.6 \\
\hline Both & 59.0 & 54.2 & $-8.1 \%$ & -4.8 \\
\hline \multicolumn{5}{|c|}{ Predicted data $†$} \\
\hline \multicolumn{5}{|c|}{ All cancers } \\
\hline Men & 300.5 & 299.2 & $-0.4 \%$ & -1.3 \\
\hline Women & 174.6 & 172.9 & $-1.0 \%$ & -1.7 \\
\hline \multicolumn{5}{|l|}{ Lung cancer } \\
\hline Men & 111.3 & 137.0 & $+23.1 \%$ & +25.7 \\
\hline Women & 38.3 & 53.6 & $+39.6 \%$ & +15.3 \\
\hline
\end{tabular}

Observed death rates (per 100000) standardised to US standard population. Data from Ries et al.' Predicted lung cancer death rates represent straight line projections to 2003 from the periods 19501975 in men and 1975-1990 in women. Predicted all cancer death rates represent the observed all cancer rate plus the difference between the predicted and observed lung cancer death rates. 


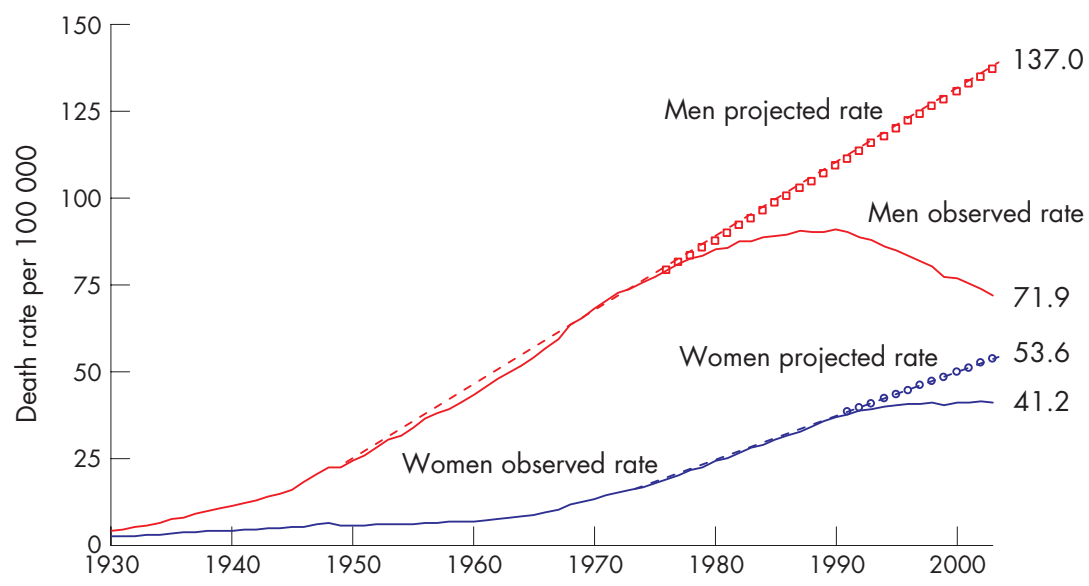

Figure 1 Observed and project lung cancer death rates, United States, 1930-2003. The observed death rates, indicated by solid lines, are based on US Mortality Public Use Data Tapes, 19602003, and US Mortality Volumes 1930-1959, published by the National Center for Health Statistics, Centers for Disease Control. The rates are standardised for age to 2000 US standard million population. The dotted lines represent straight line projections of the observed slope from 1950-1975 in men and from 1975-1990 in women.

rate increased most steeply from 1975 to 1990 and then levelled off, but did not decrease through $2003 .^{5}$

Our second method was to project what might have happened to cancer mortality rates had there been no reductions in smoking since the 1950s. We assumed that the lung cancer death rate would have continued to rise through 2003 as steeply as it had in the period 1950-1975 for men and 1975-1990 for women. The dotted lines in fig $\mathrm{l}$ and the predicted values in table 1 indicate what would have happened to lung cancer death rates under this scenario. The predicted lung cancer death rate is higher than the observed rate in both 1991 and 2003 in

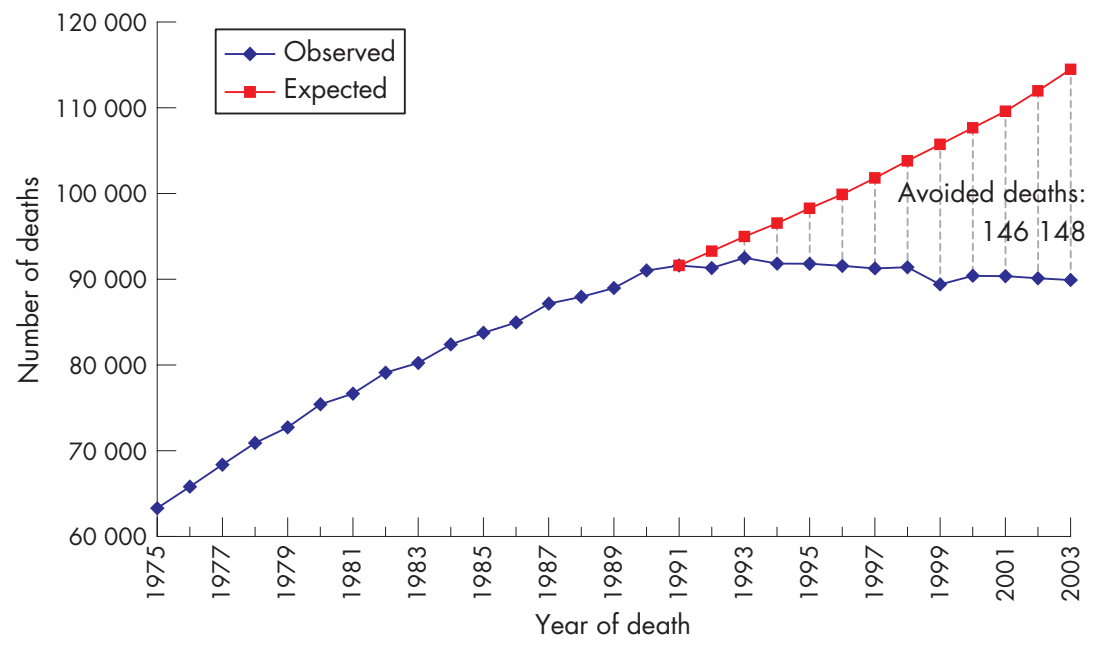

Figure 2 Trends in the observed and expected number of lung cancer deaths in US men, 19752003. The blue line represents the observed number of lung cancer deaths in US men from 1975 to 2003 , based on US vital statistics data. The red line indicates the number of lung cancer deaths that would have been expected from growth and aging of the US population through 2003, had the age-specific rates remained unchanged from 1991 through 2003. The hatched section represents the number of lung cancer deaths avoided because of the decrease in death rates after 1991. prevent further increases. This may or may not be true. Certainly the lung cancer death rate in men would have continued to increase beyond its peak of 90.6 per 100000 in 1990, as was the case in the United Kingdom ${ }^{6}$ and Hungary $^{7}$ where smoking prevalence was allowed to increase for longer before the introduction of control measures. In these countries the lung cancer death rate in men (standardised to the US 2000 age distribution) peaked at 114.5 in 1977 in England ${ }^{6}$ and at 120.5 in Hungary in $1995 .^{7}$ Smoking prevalence in the United Kingdom peaked at $71 \%$ and $67 \%$ among men aged $25-34$ and 35-59 years, respectively in 1948$52 . .^{6}$ In contrast, the prevalence of current cigarette smoking among adult men in the United States decreased after reaching $52.5 \%$ in $1966 .{ }^{8}$

\section{CANCER DEATHS PREVENTED}

Our third approach to estimate the impact of reductions in smoking on cancer mortality in the United States considered the number of cancer deaths avoided rather than the reduction in death rates. We recognise the limitations of dealing with numerator data only (in this case deaths from cancer). Epidemiologists prefer to measure agestandardised rates rather than the number of people affected, because rates control for growth and aging of the population, whereas the number of people affected does not. However, despite this limitation, it is informative to consider the number of cancer deaths prevented or postponed by reductions in smoking, because this measure may help communicate the benefits of tobacco control to policymakers and the public.

Accordingly, we estimated the number of cancer deaths that were prevented or postponed between 1991 and 2003 because of the reduction in the lung cancer death rate in men (fig 2). The blue line depicts the actual number of lung cancer deaths that occurred each year from 1975 to 2003, based on national vital statistics data, ${ }^{6}$ whereas the red line shows the number that would have been expected each year between 1991 and 2003, had the 1991 lung cancer death rates continued unchanged through 2003 instead of decreasing. As shown, the observed number of lung cancer deaths in men remained relatively constant from 1991 to 2003, because the decrease in the agestandardised and age-specific death rates was large enough to offset the growth and aging of the population. However, had the lung cancer death rate in 1991 persisted through 2003, then the number of lung cancer deaths would have increased each year because of 
demographic changes in the population. The divergence of the red and blue lines in fig 2 indicates that about 146000 lung cancer deaths were prevented or postponed by the decrease in the agespecific lung cancer death rates in men between 1991 and 2003.

Even though this method considers only the observed change in lung cancer between 1991 and 2003, and like our first approach underestimates the full benefit of reductions in smoking on cancer mortality, it illustrates that a large number of deaths from lung cancer were avoided because of the decrease in the lung cancer death rate in men during this period. This in turn reflects reductions in cigarette smoking that occurred because of anti-smoking messages and other tobacco control measures implemented since the 1950s.

\section{CAVEATS}

Several caveats should be mentioned regarding these estimates. As noted, restricting these analyses to lung cancer without considering other smokingrelated cancers may underestimate the contribution of reductions in smoking by up to $20 \%$. It would not be feasible to consider trends in all of the smokingattributable cancers in a brief editorial. Offsetting this underestimate, at least partly, is that we also ignored other risk factors for lung cancer, such as exposures to carcinogens in occupational settings that also have changed since the 1950s. Despite these limitations, we believe that the true contribution of reductions in smoking to the reduction in cancer death rates is within the range of our estimates.

The future benefits of reductions in smoking, derived from investments in tobacco control over the last half century, will be considerably larger than is their current impact on cancer mortality if current trends continue. Most of the reductions in lung cancer mortality that we are seeing now are only in men and largely reflect successful smoking cessation rather than decreases in smoking initiation among the young. Even the earliest birth cohorts in which adolescents who would otherwise have started smoking did not because of anti-tobacco measures, are only now reaching the age of 60 . The impact of these birth cohorts on cancer rates will increase as they continue to age and reach the age range where most smoking-attributable cancers occur.

\section{CONCLUSION}

Even our most conservative estimate indicates that reductions in lung cancer, resulting from reductions in tobacco smoking over the last half century, account for about $40 \%$ of the decrease in overall male cancer death rates and have prevented at least 146000 lung cancer deaths in men during the period 1991 to 2003. A more realistic straight line projection of what lung cancer rates might have become suggests that, without reductions in smoking, there would have been virtually no reduction in overall cancer mortality in either men or women since the early 1990s. The payoff from past investments in tobacco control has only just begun. The aging of birth cohorts with lower smoking initiation rates and the anticipated future decrease in lung cancer mortality in women will help to sustain progress. It is unclear how long the recent decrease in the number of Americans dying of cancer will continue, given the size of the "baby boomer" generation, even though the 2004 preliminary mortality data covering over $90 \%$ of the total US deaths ${ }^{9}$ suggest that the decrease will continue in the near term. What is certain is that sustained progress in tobacco control is essential if we are to continue to make progress against cancer.

Tobacco Control 2006;15:345-347.

doi: $10.1136 /$ tc. 2006.017749

\section{Authors' affiliations}

M J Thun, A Jemal, Department of

Epidemiology and Surveillance Research, American Cancer Society, Atlanta, Georgia, USA

Correspondence to: Michael J Thun, MD, Department of Epidemiology and Surveillance Research, American Cancer Society, Atlanta, GA 30229-4251, USA; mthun@cancer.org

\section{REFERENCES}

1 Ries L, Harkins D, Krapcho M et al. SEER cancer statistics review, 1975-2003. Bethesda, Maryland: National Cancer Institute, 2006.

2 International Agency for Research on Cancer. Tobacco smoke and involuntary smoking, vol 83. Lyon: IARC, 2004

3 US Department of Health and Human Services. The health consequences of smoking: a report of the Surgeon General. Rockville, Maryland: US Department of Health and Human Services, Centers for Disease Control and Prevention National Center for Chronic Disease Prevention and Health Promotion, Office On Smoking and Health, 2004.

4 National Center for Health Statistics. DoVS. (Accessed June 2006).

5 Jemal A, Siegel R, Ward E, et al. Cancer statistics, 2006. CA Cancer J Clin 2006;56:106-30.

6 Peto R, Darby S, Deo H, et al. Smoking, smoking cessation and lung cancer in the UK since 1950: combination of national statistics with two case-control studies. $B M$ 2000;321:323-9.

7 Peto R, Lopez A, Boreham J, et al. Mortality from smoking in developed countries 1950-2000. New York: Oxford University Press, 1994.

8 Centers for Disease Control and Prevention. Surveillance for selected tobacco-use behaviors United States, 1900-1994. MMWR CDC Surveill Summ 1994;43(No. SS-3): 1-43

9 Hoyert DL, Kung HC, Smith BL. Deaths: preliminary data for 2003. Natl Vital Stat Rep 2005;53:1-48. 


\section{What this paper adds}

- Numerous cross-sectional studies have shown that the socioeconomic characteristics of residential areas are independently associated with residents' smoking, and that smoking prevalence increases with area deprivation.

- This longitudinal examination of smokers who lived at the same address between 1991 and 1997 suggests that deprivation characteristics of areas may influence smoking behaviour.

- The findings imply that some (currently unknown) attribute of living in a deprived area may contribute to its residents' worse smoking profiles and lower prevalence of quitting.

\section{Authors' affiliations}

K Giskes, F J van Lenthe, J Brug, J P Mackenbach, Department of Public Health, Erasmus Medical Centre, Rotterdam, The Netherlands K Giskes, G Turrell, School of Public Health/Institute of Health and Biomedical Innovation, Queensland University of Technology, Brisbane, Queensland, Australia

Funding: KG is supported by an Australian National Health and Medical Research Council (NHMRC) Sydney Sax International Post Doctoral Fellowship (grant identification number: 290540). FvL is supported by a grant from the Netherlands Organisation for Scientific Research (NWO grant number 904-66-104). GT is supported by an Australian National Health and Medical Research Council/National Heart Foundation Career Development Award (CR 01B 0502). The GLOBE study is carried out by the Department of Public Health of the Erasmus Medical Center, Rotterdam in collaboration with the Public Health Services of the city of Eindhoven and South-East Brabant region.

Competing interests: None declared.

Correspondence to: K Giskes, Department of Public Health, Erasmus Medical Centre, Rotterdam 3000DR, The Netherlands;

k.giskes@erasmusmc.nl

Received 13 January 2006

Accepted 11 August 2006

\section{REFERENCES}

1 Ecob R, Macintyre S. Small area variations in health related behaviours; do these depend on the behaviour itself, its measurement, or on personal characteristics? Health Place 2000;6:261-74.

2 Shohaimi S, Luben R, Wareham N, et al. Residential area deprivation predicts smoking habit independently of individual educational level and occupational social class. A cross sectional study in the Norfolk cohort of the European Investigation into Cancer (EPIC-Norfolk). J Epidemiol Community Health 2003;57:270-6.

3 Reijneveld S. The impact of individual and area characteristics on urban socioeconomic differences in health and smoking. Int J Epidemiol 1998;27:33-40.

4 Duncan C, Jones K, Moon G. Smoking and deprivation: are there neighbourhood effects? Soc Sci Med 1999;48:497-505.

5 Diez Roux A, Link B, Northbridge $M$. A multilevel analysis of income inequality and cardiovascular disease risk factors. Soc Sci Med 2000;50:673-87.

6 Mackenbach J, van de Mheen H, Stronks K. A prospective cohort study investigating the explanation of socioeconomic inequalities in health in the Netherlands. Soc Sci Med 1994;38:299-308.

7 Droomers M, Schrijvers C, Mackenbach J. Why do low educated people continue smoking? Explanations from the longitudinal GLOBE study. Health Psychol 2002;21:262-72.

8 van Lenthe F, Mackenbach J. Neighbourhood deprivation and overweight: the GLOBE study. Int J Obes 2002;26:234-40.

9 van Lenthe F, Brug J, Mackenbach J. Neighbourhood inequalities in physical activity: the role of neighbourhood attractiveness, proximity to local facilities and safety in the Netherlands. Soc Sci Med 2005;60:763-75.

10 Ormel J. Moeite met leven of een moeilijk leven (Difficulties with living or a difficult life). Groningen, The Netherlands: Rijksuniversiteit Groningen, 1980.

11 Sanderman R, Arrindel W, Ranchor A, et al. Het meten van persoonlijkheidskenmerken met de Eysenck Personality Questionniare (EPQ): een handleiding (The measurement of personality characteristics using the Eysenck Personality Questionnaire (EPQ): a manual). Groningen, The Netherlands: Noordelijk Centrum voor Gezondheidsvraagstukken, 1995.

12 Schrijvers C, Stronks K, van de Mheen H, et al. Explaining educational differences in mortality: the role of behavioural and material factors. Am J Public Health 1999;89:535-40.

13 Rasbash J, Browne W, Goldstein H, et al. A user's guide to MLwiN. London: University of London, 2000.

14 Stead M, MacAskill S, MacKintosh A, et al. It's as if you're locked in: qualitative explanations for area effects on smoking in disadvantaged communities. Health Place 2001;7:333-43.

15 Wiltshire S, Bancroft A, Amos A, et al. They're doing people a servicequalitative study of smoking, smuggling and social deprivation. BMJ 2001;323:203-7.

16 Copeland L. An exploration of the problems faced by young women living in disadvantaged circumstances if they want to give up smoking: can more be done at general practice level? Fam Pract 2003;20:393-400.

\section{CORRECTION}

doi: 10.1136/tc.2006.17749corr l

In the October editorial, How much of the decrease in cancer death rates in the United States is attributable to reductions in tobacco smoking? (Tobacco Control 2006;15:345-7) an error has occurred in the table. The observed death rate from all cancers combined among women in 1991 was 175.3 per 100000 (not 17303). The percentage decrease in the death rate from 1991 to 2003 was $-8.4 \%$ (not $8.5 \%)$. The journal apologises for this error. 